\title{
Application of syringosubarachnoid shunt through key-hole laminectomy
}

\author{
Technical note
}

\author{
Ferruh Gezen, M.D., Serdar Kahraman, M.D., Ibrahim M. ZiYal, M.D., \\ ZAFEr ÇANaKÇı, M.D., AND AbDURRahMan BaKır, M.D.
}

Department of Neurosurgery, School of Medicine, The Abant Izzet Baysal University, Düzce, Turkey; and Department of Neurosurgery, Gülhane Medical School, Ankara, Turkey

\begin{abstract}
The authors describe the key-hole laminectomy technique (KHLT) for application of syringosubarachnoid shunts This technique was used in 29 patients with noncommunicating syringomyelia. In all cases the shunts were inserted successfully without any peri- or late postoperative complications. The late follow-up magnetic resonance examinations revealed the clear collapse of syrinx in all cases. The authors advocate use of the KHLT because it is associated with less surgery-related trauma, epidural fibrosis, infection, and spinal instability.
\end{abstract}

\section{KEY WORDS • key-hole laminectomy • syringomyelia • syringosubarachnoid shunt}

Despite the fact that multilevel hemilaminectomies or total laminectomies provide a wide exposure of the spinal cord for the surgical treatment of syringomyelia, spinal tumors, and other pathological lesions, many complications such as extensive epidural fibrosis, spinal instability and deformity, nerve root compression and infection have been frequently observed. ${ }^{1-8,11-13}$ With the use of an operating microscope, limited removal of bone structures and ligamentum flavum enables preservation of as much of the normal anatomical structures as possible, with fewer peri- and late postoperative complications. Accordingly, the KHLT was used to place a syringosubarachnoid shunt for the surgical treatment of syringomyelia. We present our experience and summarize the treatment results.

\section{CLINICAL MATERIAL AND METHODS}

During a 6-year period, 29 patients with noncommunicating syringomyelia were treated using the KHLT for the application of a syringosubarachnoid shunt. Eighteen pa-

Abbreviations used in this paper: DREZ = dorsal root entry zone; $\mathrm{KHLT}=$ key-hole laminectomy technique; MR = magnetic resonance; SSEP = somatosensory evoked potential. tients were men and 11 were women. The mean age was 37 years (range 19-62 years). All patients were evaluated using MR imaging scans and SSEP monitoring. Fourteen patients had pure cervical noncommunicating syringomyelia, nine patients had cervicodorsal syringomyelia, four patients had syringomyelia dorsal, and two patients had holocord syringomyelia. The criteria for application of the shunt was the presence of symptomatic and noncommunicating syringomyelia with a large isolated syrinx. Those patients in whom MR imaging demonstrated marked transverse diameter of the syringomyelia cavity and signs of an incomplete cord lesion were primarily advised to undergo a syringosubarachnoid shunt placement procedure.

\section{Operative Technique:}

The patient is operated on in Concorde position (prone, thorax elevated, neck flexed and tilted away from the surgeon) after endotracheal induction of anesthesia. We make a 1-cm incision lateral from the midline and a 2-cm paramedian skin incision on the symptomatic side according to the largest level of the syringomyelia cavity (Fig. 1A). Using a microscope, the appropriate lamina is exposed. The spinous processes and interspinous ligament are left 


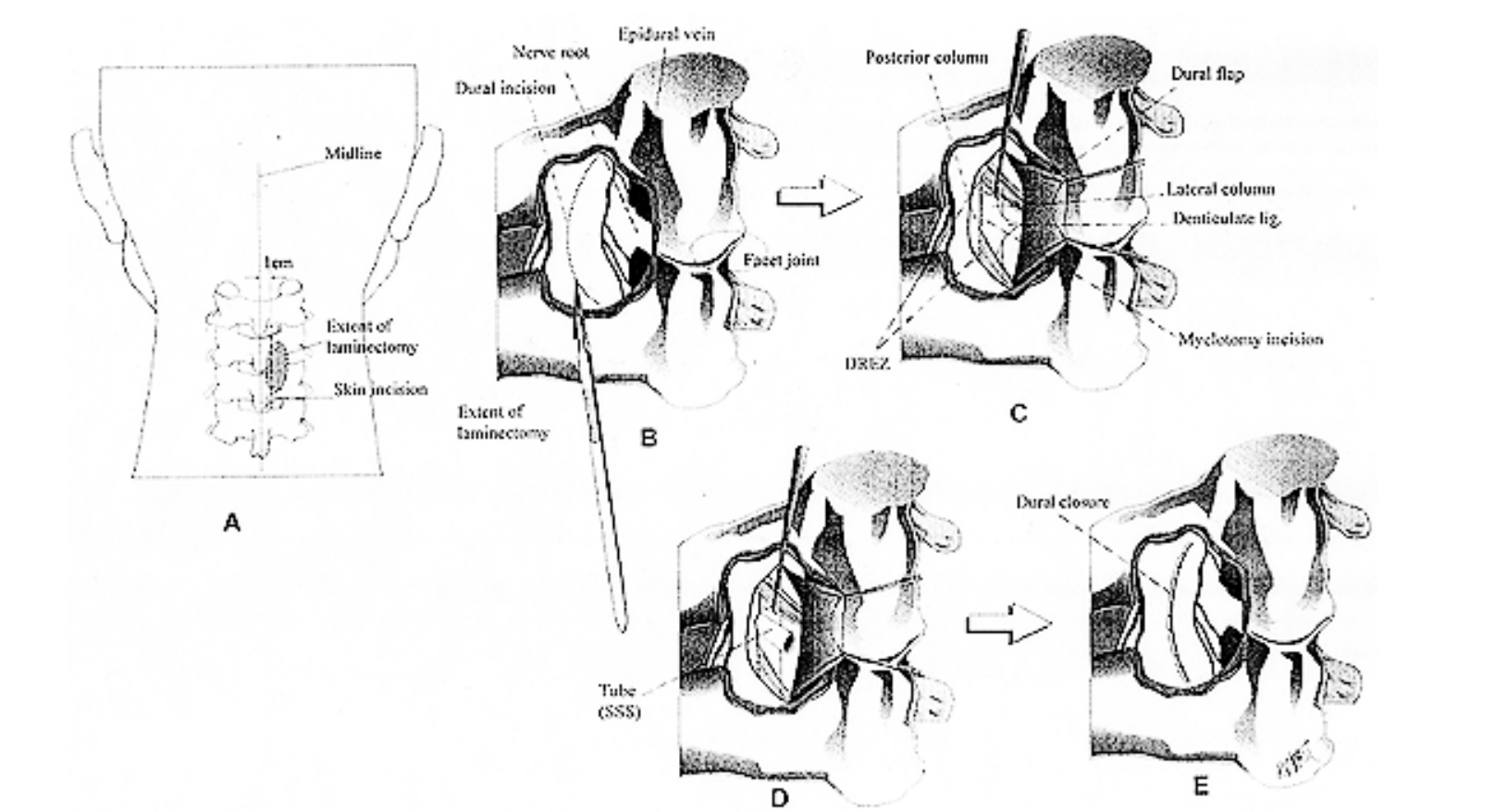

Fig. 1. Schematic drawings depicting the skin incision in KHLT for insertion of a syringosubarachnoid shunt (A), keyhole laminectomy at the C5-6 level (B), DREZ myelotomy (C), insertion of the catheter into the syrinx (D), and dural closure (E). lig = ligament; SSS = syringosubarachnoid shunt.

intact. The hemilaminae of adjacent vertebrae above and below are stripped from the paravertebral muscles subperiostally and reflected laterally as far as the facet joints are exposed (Fig. 1B). An adequate amount of bone is removed for the exposure of DREZ. The dura is opened with a half moon-shaped incision and reflected laterally (Fig. 1C). In all cases, the proximal shunt tube is inserted into the syrinx after DREZ myelotomy is performed (Fig. 1D). The closure is performed in the usual manner (Fig. 1E).

\section{RESULTS}

In all cases the shunts were succesfully inserted (Fig. 2). In the peri- and early postoperative period, no complication was observed. All patients underwent neurological examinations, MR imaging, and SSEP monitoring for a mean follow-up period of 26 months (ranging from 18-36 months). In 14 cases (48\%) neurological status improved. No neurological change was observed in the other cases, and spinal instability was shown to be absent. In all cases, MR imaging revealed the collapse of syrinx. There were no cases of moderate or severe epidural fibrosis. Marked improvement in 53\% of all cases and no impairments in the other cases were found after SSEP examinations. Additional neurological deficits, central nervous system dysfunction, spinal deformity and instability, symptomatic epidural fibrosis, and infection were not observed in any patient during follow-up period.

\section{DISCUSSION}

Rhoton $^{9}$ and Tator and associates ${ }^{10}$ first conducted the two-level hemilaminectomies for the treatment of sy- ringomyelia. However, following multilevel, standard, total and hemilaminectomies, postoperative complications such as extensive epidural fibrosis, spinal deformity and instability, and nerve root compression have been frequently observed. ${ }^{1-4,6,7,11,12}$ We used the KHLT for insertion of a syringosubarachnoid shunt to minimize the risk of surgery-related trauma, infection, scar formation, spinal instability, and spinal deformity. The posterior approach described by Kempe ${ }^{5}$ for the treatment of radiculopathy has inspired us to perform our technique. The main advantages of KHLT are that it requires only a small skin incision; limited and unilateral dissections of paravertebral

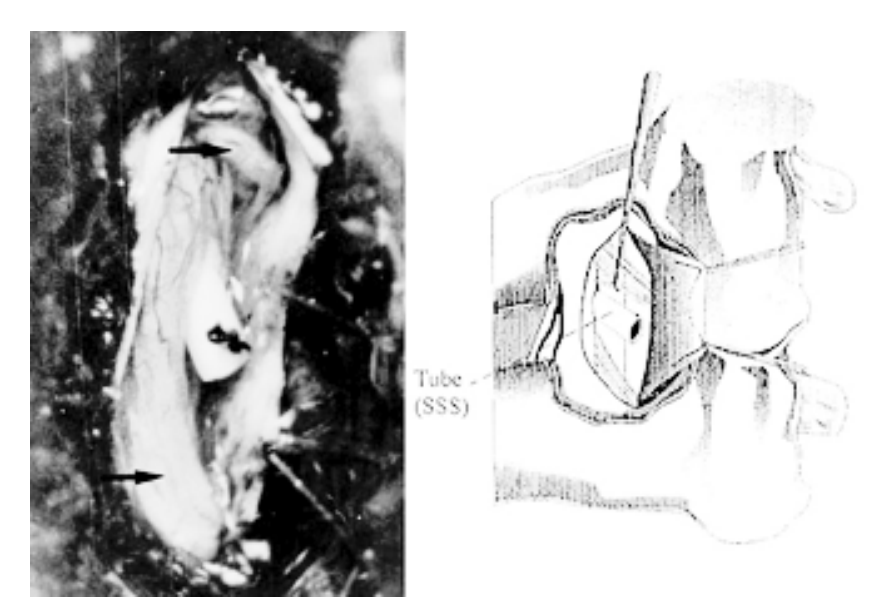

Fig. 2. Intraoperative photograph (left) schematic drawing (right) illustrating the application of a syringosubarachnoid shunt through key-hole laminectomy. SSS = syringosubarachnoid shunt. 


\section{Key-hole laminectomy in syringomyelia}

muscles, ligaments, and laminae; and limited removal of ligamentum flavum with preservation of epidural fat tissues and venous plexi. The preservation of these components provides a better healing of soft tissues and bone structures, as well as a smaller degree of epidural scar formation, deformity, and instability. Opening of the dura and insertion of the shunt into the syrinx after DREZ myelotomy was performed with ease by using the microscope in all cases. We never encountered any difficulties during this last step, which may be related to small exposure site.

In conclusion, the KHLT for the insertion of a syringosubarachnoid shunt in the treatment of syringomyelia is a safe, practical, and preferable technique associated with less risk and fewer complications, as compared with standard techniques in multilevel hemilaminectomy or total laminectomy.

\section{Acknowledgment}

The authors wish to thank to Ahmet Sinav, M.D., for his schematic drawings and assistance.

\section{References}

1. Batzdorf U, Klekamp J, Johnson JP: A critical appraisal of syrinx cavity shunting procedures. J Neurosurg 89:382-388, 1998

2. Callahan RA, Johnson RM, Margolis RN, et al: Cervical facet fusion for control of instability following laminectomy. J Bone Joint Surg (Am) 49:713-720, 1977

3. Chiou SM, Eggert HR, Laborde G, et al: Microsurgical unilateral approaches for spinal tumour surgery: eight years' experience in 256 primary operated patients. Acta Neurochir 100: 127-133, 1989
4. Eggert HR, Scheremet R, Seeger W, et al: Unilateral microsurgical approaches to extramedullary spinal tumors. Operative technique and results. Acta Neurochir 67:245-253, 1983

5. Kempe LG: Operative Neurosurgery. New York: SpringerVerlag, 1968, pp 251-256

6. Lund-Johansen M, Wester K: Syringomyelia treated with a nonvalved syringoperitoneal shunt: a follow-up study. Neurosurgery 41:858-865, 1997

7. Mikawa Y, Shikata J, Yamamuro T: Spinal deformity and instability after multilevel cervical laminectomy. Spine 12:6-11, 1987

8. Milhorat TH, Johnson WD, Miller JI, et al: Surgical treatment of syringomyelia based on magnetic resonance imaging criteria. Neurosurgery 31:231-245, 1992

9. Rhoton AL Jr: Microsurgery of syringomyelia and syringomyelic cord syndrome, in Schmiedek HH, Sweet WH (eds): Operative Neurosurgical Techniques: Indications, Methods, and Results, ed 2. Orlando, FL: Grune \& Stratton, 1988, pp 1307-1326

10. Tator $\mathrm{CH}$, Meguro K, Rowed DW: Favourable results with syringosubarachnoid shunt for treatment of syringomyelia. J Neurosurg 56:517-523, 1982

11. Yaşargil MG, Tranmer BI, Adamson TE: Unilateral partial hemilaminectomy for the removal of extra- and intramedullary tumors and AVMs. Adv Tech Stand Neurosurg 15:113-132, 1991

12. Yasuoka S, Peterson HA, MacCarty CS: Incidence of spinal column deformity after multilevel laminectomy in children and adults. J Neurosurg 57:441-445, 1982

13. Zeidman SM, Ducker TB: Posterior cervical laminoforaminotomy for radiculopathy: review of 172 cases. Neurosurgery 33: $356-362,1993$

Manuscript received December 10, 1999.

Accepted in final form February 9, 2000.

Address reprint requests to: Ferruh Gezen, M.D., Barbaros Bulvarı, 61/2, Beşiktaş, Istanbul, Turkey. 